\title{
Energy-efficient multi-loop heating systems for multi-apartment residential buildings
}

\author{
Andrey Benuzh ${ }^{1, *}$, Sergey Fedorov ${ }^{2}$ \\ ${ }^{1}$ Central Research and Design Institute of the Ministry of Construction and Housing and Communal \\ Services of the Russian Federation, Vernadskogo Avenue, Building 29, Moscow, 119331, Russia \\ ${ }^{2}$ National Research Moscow State University of Civil Engineering, Yaroslavskoe shosse, 26, \\ Moscow, 129337, Russia
}

\begin{abstract}
The paper analyzes the connection diagrams and operation of buildings heat supply systems, taking into account the impact of changing weather and climate influences during the heating season. High-quality central heat consumption control was carried out, at which the heating carrier flow rate was maintained at a constant level, and its temperature varied according to a predetermined schedule. Thermal characteristics or mode of operation of the building differed from the data set in the schedule, as a result, more heat was consumed in certain periods. Its overrun was also observed during the warm period of the heating season, when, due to the maintenance of the hot water temperature at the right level on the outlet from the water-heaters, the heating carrier from the source was supplied with a temperature exceeding the established norms. The results of field tests and the diagrams of heat supply for heating at the heat supply operation in central heating points are presented. The main accent is made on the study of multi-circuit heating systems with frontal control of heat supply.
\end{abstract}

\section{Introduction}

During the period of mass construction and commissioning of residential areas, heat supply systems with central heating points (CHP), through which heat was supplied through separate pipelines for heating and hot water supply of the buildings, were widely used. It was necessary to ensure the air temperature in the apartments no lower than the minimum permissible level $\left(+18{ }^{\circ} \mathrm{C}\right)$. When the public complains about the low temperature in the premises, local violations in the heating system were not eliminated often, and the heat consumption of all buildings supplied from this central heating point increased [1-4].

This led to the increase in the temperature of the heat supply agent in the return pipeline, overloading of the main pipelines and a chronic lag in the operation mode of the end consumers. As a result, majority of the heating networks operated in excess of the estimated water consumption for 30-40\%. It was considered satisfactory if the temperature of the water returned to the source corresponded to the required indices without taking into account its cooling in the water heaters of the 1 st stage of hot water supply $[5,6]$.

* Corresponding author: ABenuzh@gmail.com 
The overall picture was aggravated by the fact that major budgets were used to create heat and power plants (CHP), and the heat networks were financed on the leftover principle. As a result, the thermal insulation of the pipelines was of very poor quality, the drainage was blocked and did not fulfill its function of preventing the flooding of networks, and the heating points in the buildings were not equipped with efficient systems for supplying heat to heating. The control of heat supply system depending on changes in the outdoor temperature was carried out centrally at the source [7-10].

In a number of European countries, for example, in Denmark, where centralized heat supply from CHP plants found wide use, due attention was paid to improving both the electrical component of the generated energy and the heat supply. High-quality thermal insulation of pipelines using polyurethane foam and the implementation of an airtight coating layer that prevents the flooding of the insulation by groundwater was developed. It was forbidden to connect consumers to heat networks without providing them with heat supply automatic control devices for heating and hot water supply and without considering the amount of heat consumed [11]. In addition to economical heat consumption by consumers, this allowed for heat supply from the source according to the method of quantitative central control, according to which the heating carrier temperature is maintained at a constant level, changing stepwise 2-3 times during the heating season, and the flow rate of the heating carrier circulating in the heating networks varies according to need. This decision contributed to the work of several heat sources, including waste incineration enterprises, on a single heating network, which dramatically increased the efficiency of heat supply [12-13].

\section{Materials and Methods}

When calculating the parameters of the heating carrier for domestic heat supply and heating systems, we proceeded from the achievement of the lowest cost of equipment. The higher the temperature of the heater, the less can be the surface of its heat transfer, and, accordingly, less weight and cost of devices. Therefore, the upper level of the calculation temperature in the supply pipe of the heating system corresponded to the value $+95^{\circ} \mathrm{C}$. In case of exceeding this threshold, the dust was sublimated, accompanied by an unpleasant smell. In connection with the use of finned convectors as heating devices, the calculated coolant temperature rose to $+105^{\circ} \mathrm{C}$, since on the surface of the fins, the temperature did not exceed the previous $+95^{\circ} \mathrm{C}$.

The lower value of the heating carrier temperature in the return pipeline was determined based on the fact that the average temperature of the heater remained high enough to prevent the negative effect of a decrease in the heating carrier flow rate when the return water temperature decreases, since the range of pipelines was limited to a diameter of 15 $\mathrm{mm}$, which made it difficult to ensure the hydraulic stability of the heating system. As a compromise solution, the value of the calculated return water temperature of $+70^{\circ} \mathrm{C}$ was chosen, although from the district heating point of view, it was advisable to lower it to increase electricity generation at heat consumption.

The upper value of the calculated temperature of the heating carrier circulating in the heating networks was determined by the non-boiling pressure of overheated water. Therefore, sought to raise it, because in this case, the heating carrier flow rate decreased, and this led to a decrease of the heat pipes diameter and a cost reduction of electricity for pumping the heating carrier. At first, as a calculated temperature in the supply pipe of heat networks, $+130^{\circ} \mathrm{C}$ was taken, later it was raised to $+150^{\circ} \mathrm{C}[14]$.

Abroad, they proceeded from considerations of durability of pipelines buried in the ground. It was considered that the higher the temperature of the heating carrier, the greater the deformation forces caused by the linear expansion of the metal of the pipes, and the 
pipelines collapse faster. Therefore, in many countries they strive to reduce the design parameters of the coolant temperature both in heating systems and in heat supply networks, even though this leads to the increase in heating carrier flow rate and a corresponding increase in costs for the networks construction. For example, in Copenhagen heat networks, the design parameters of the heating carrier are in the range of $+115^{\circ} \mathrm{C}$ to $+55^{\circ} \mathrm{C}$, and in heating systems - from $+70^{\circ} \mathrm{C}$ to $+55^{\circ} \mathrm{C}$. At the same time, there is a tendency to their further decrease, despite the fact that the range of the networks exceeds $20 \mathrm{~km}$.

Therefore, in our country, with the expected increase in the cost of repairs, preference should be given to preserving the durability of heat pipes and, where possible, to reduce the calculated parameters of the heating carrier. It will also increase the comfortable conditions of stay in heated premises, as with increasing the buildings thermal protection, heat losses of the buildings decrease, and the heater becomes so small that when it is installed under the window, it does not block the effect of negative radiation from the window surface. Reducing the parameters of the heating carrier will require the increase in the surface area of the heater and, accordingly, its length, which will allow covering most of the window with convective currents of warm air.

Reducing the parameters of the heating carrier in the heating system will increase the efficiency of control of the functioning of heating devices using thermostats, since this reduces unregulated heat transfer from the risers of the heating system, increases the contribution of the heating device to compensate for heat loss in the room. In Germany, for example, to increase the efficiency of using thermostats, heat insulation of heating pipes is implemented.

A solution is known which consists in transferring hot water preparation centers to domestic needs closer to the points of its consumption, i.e. in a heated building. This eliminates the need for a central heating point and quarter hot water networks. Such a solution not only improves the quality of hot water supply to residents, but also, as was shown in the 1970s, calculations are more economical in terms of capital costs and annual operating costs. This reduces heat losses, energy consumption for pumping and circulation of hot water, increases the efficiency of heating in general. However, at that time the industry was not ready for the implementation of heat supply points with hot water heaters in each house, although the regulatory documentation stated that the central heating point can be used only during a feasibility study.

However, the central heating point continued to be commissioned. Efforts were aimed at obtaining the highest possible heat savings based on control of operating modes of the central heating points. The control system of a central heating station with a two-stage mixed scheme for connecting hot water heaters and limiting the maximum flow rate of network water was developed and implemented in a typical project (Fig. 1). According to this scheme, in the hours of maximum water consumption, the heat supply to the heating was reduced. During periods of water consumption below the average, this underheating was compensated by increasing the thermal parameters in the heating schedule. On average, the balance of heat for heating and hot water was observed per day, with the heat carrier flow not exceeding the value determined based on the average hourly heat consumption for the hot water supply.

Such a solution allows stabilizing the operation of heat networks, eliminating the effect of uneven heat consumption on the hot water supply on them. A mixed scheme of connection of water heaters is used at that, because the traditional two-step sequential circuit does not allow for efficient control of the heat supply. Implementation of this scheme prevents the negative consequences of the operation of heating networks in the fuel shortage mode and does not allow to increase the estimated consumption of network water at the central heating point, which would take place as compensation for the insufficient temperature in the heating network supply system. 


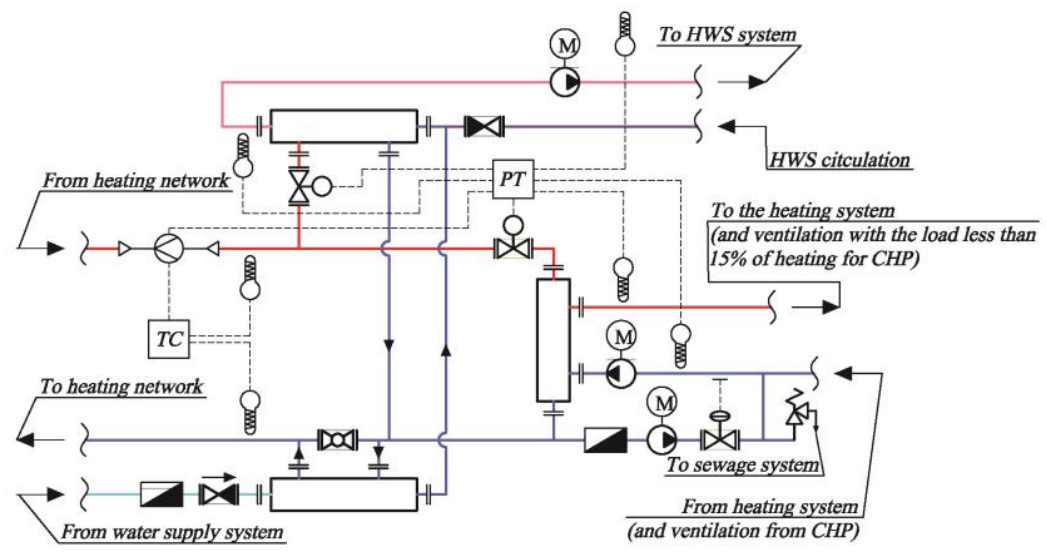

Fig. 1. Circuit diagram of CHP with independent connection of district heating networks and control of heat supply for heating and hot water supply with limiting the maximum flow of water from the heating network.

\section{Results}

As part of the implementation of the presented methodology, cost-effective heat supply schedules for heating were developed considering the internal heat generation in apartments. In contrast to the heat losses of a building, the internal heat generation, constituting $20-25 \%$ of the heat losses value in the calculation conditions, does not depend on the outdoor temperature. Therefore, with an increase of the outdoor temperature, their share in the heat balance of the building increases. Due to this, it is possible to reduce the supply of heat to heating despite the central control schedule, which does not take this circumstance into account (Fig. 2). As it was shown by field tests of such a regime in the central heating point of a residential district, the heat savings for heating are $11-15 \%$ compared to the mode without implementing such heat supply control, but with the stabilization of the network water flow at the central heating point with a two-step sequential connection scheme for water heaters. 

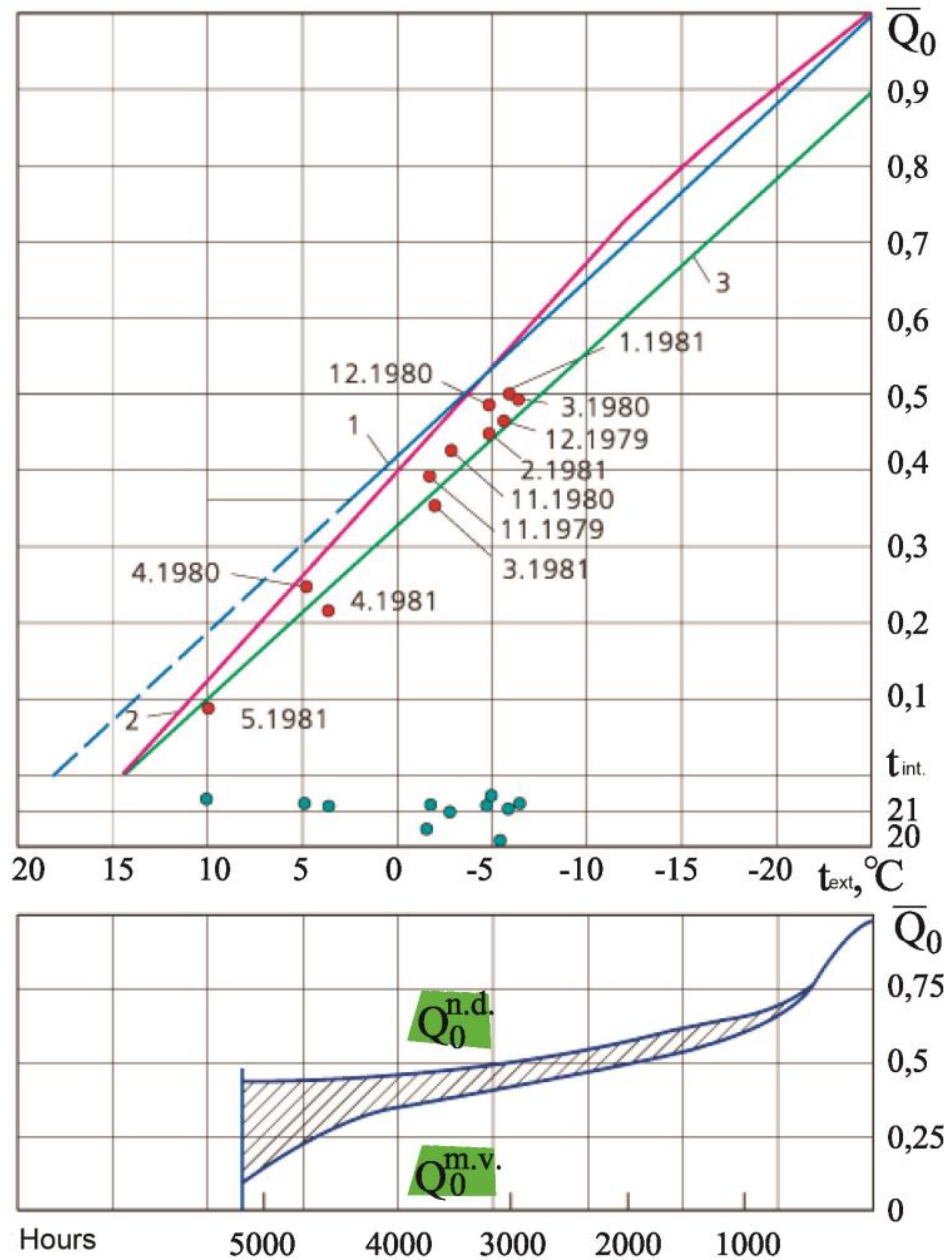

Fig. 2. The results of field tests and calculated schedules of the heat supply for heating at the heat supply control from CHP.

Significant heat savings are achieved with the implementation of the correction of the heat supply schedule, depending on the deviation of the internal air temperature in buildings from the set values. The schedule of the choice of the heating carrier parameters depending on the change in the outside temperature is realized provided that the average temperature in the premises does not deviate from the setpoint $\left(+21{ }^{\circ} \mathrm{C}\right)$. Otherwise, the schedule is adjusted. With centralized heat operation, this allows, in addition to maintaining the set air temperature, to obtain additional heat savings by reducing its supply in the absence of wind and partially consider heat gains from solar radiation. 
Fig. 2 shows the results of measuring the actual heat consumption for heating obtained during two heating seasons with the heat supply control in the central heating point and the curve of the calculated heat consumption according to the existing schedule.

Schedule 1 (Fig. 2) corresponds to the heat supply without considering the permanent household heat generation. The points on the schedule show the average heat consumption per month. Accounting for permanent household heat generation and air exchange with the windward orientation is reflected using schedule 2 . It shows that the provided surcharge for the wind was used only in certain periods. In general, during the heating season, the actual heat consumption approached the required values for the leeward orientation. The additional heat savings from correction of the internal temperature schedule is $6-8 \%$ (Fig. 2 ). At the same time, comfortable conditions in the premises are observed (the mean monthly air temperature values in the apartments are indicated by green dots). It is important that the savings are achieved in the cold period of the year and allows to substantially eliminate the waste of heat that occurs due to the poor quality of the windows.

Since overestimation of the heat supply may not affect the internal air temperature, in the process of heat consumption control, it is necessary to change, not depending on the outdoor temperature, not the water temperature according to a predetermined schedule, but the heat consumption itself. This will help to avoid errors due to inconsistencies between the actual and calculated thermal characteristics of the heating system. The parameters of the heat consumption schedule are determined by calculating heat losses, infiltration and internal heat release in the building. This schedule, as a rule, is linear, which facilitates its implementation by maintaining the temperature difference between the heating carrier in the supply and return pipelines.

\section{Discussion}

The solutions analyzed above for controlling the heat supply from central heating point can also be implemented at an individual heating point. Transition to individual heating points (IHP) allows to achieve even greater heat savings using facade heat supply control (Fig. 3).

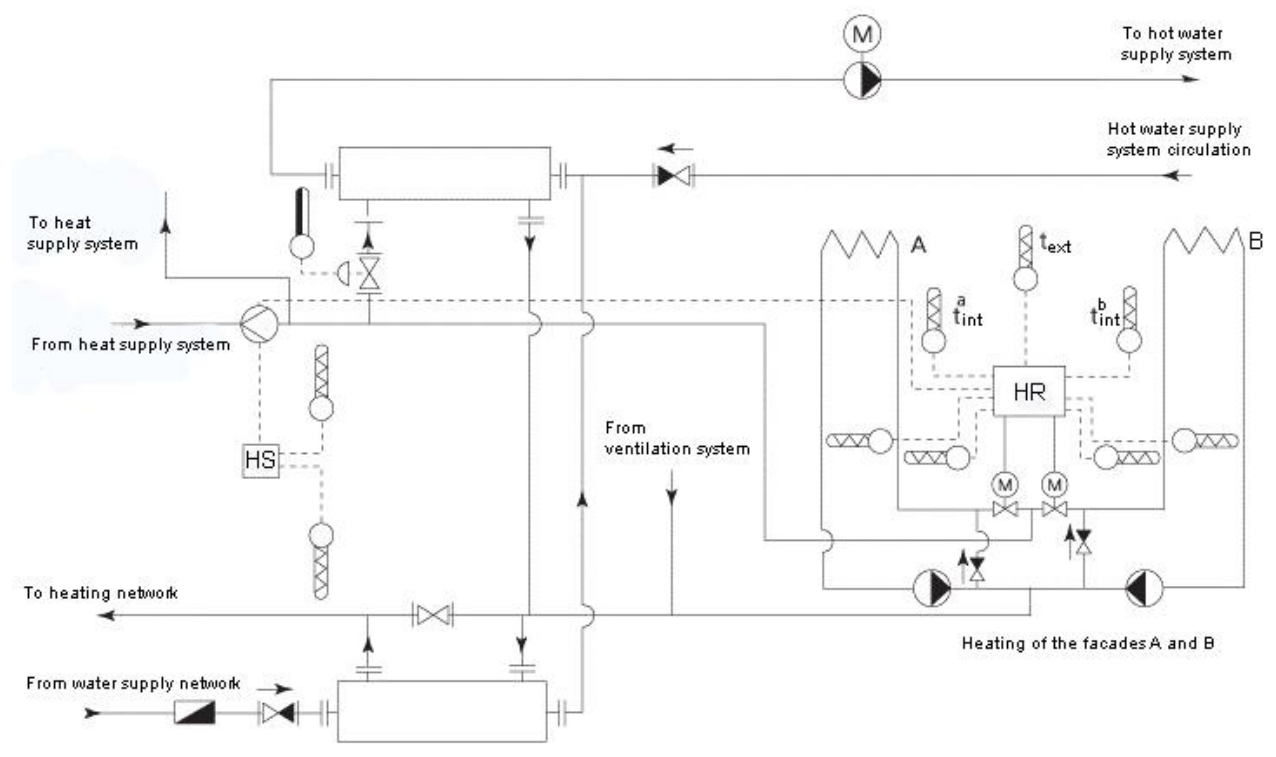

Fig. 3. ITP scheme with facade heat control 
Such a solution is especially effective in the reconstruction of existing long, multisection buildings performed without replacing the heating system. Facade control of heat supply is not inferior to the solution with thermostats. At the same time, its implementation is much cheaper in terms of major costs and does not require the welding work required for installation of thermostats in apartments.

The use of multi-circuit heat supply systems with facade heat supply control allows saving up to $15-20 \%$ of thermal energy in the process of heating of buildings that are long in plan.

These systems consider the fact that during the autumn-spring heating period in the rooms located on the south side of the building it is much warmer than in the rooms of the opposite facade. Therefore, each facade of the building is equipped with a separate heat management system. At the same time, the connection of the heating system to the heat source can be realized in a dependent or independent scheme.

Façade control of heat supply can be carried out by the deviation of the internal temperature in the premises, by the disturbance and by the joint use of both methods. In contrast to local heat supply control, in systems with facade heat supply, when determining the mode of heat consumption, not only the change in the outdoor temperature is considered, but also the influence of wind and solar radiation.

At the same time, the issues of organizing the collection of information on the environmental parameters used become important. As one of the solutions, it was proposed to use a gradual connection of several semiconductor temperature sensors, which in practice does not reflect the real distribution of temperature indicators considered. In addition, systems with centralized measurement of external thermal effects parameters can be used. In this case, the weather sensors are installed in a special meteorological point common to the district. The disadvantage of such solutions is that they do not consider the influence of external conditions on specific buildings.

The implementation of facade control has a particular relevance for the heat supply maintenance five- or nine-store houses built in the 1950s - 1970s without garret. In these buildings, supply and return lines are laid in the basement, in which it is convenient to perform welding works for laying jumpers that unite the front lines of individual sections.

At the top of fig. 4, the existing scheme is shown, in accordance with which the vertical risers of the sectional heating systems of a residential house are connected. Bottom of the fig. 4 illustrates the switching of the facade branches of different sections by jumpers into two independent frontal heating systems serving both sections of the house. 

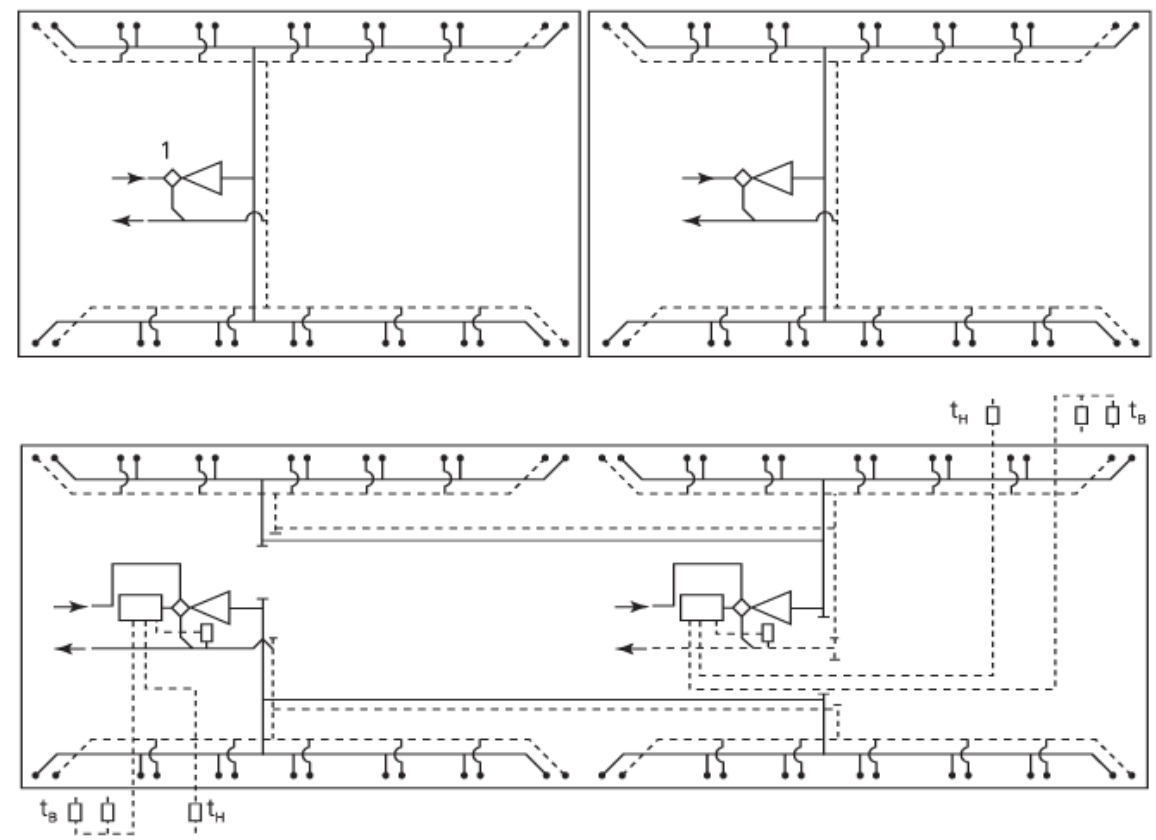

Fig. 4. Switching sectional heating systems to the façade heat supply

The practice of using the façade heat supply control in residential buildings has shown that when the outside air temperature is from $+5^{\circ} \mathrm{C}$ to $+8^{\circ} \mathrm{C}$, the heating of the facade illuminated by the sun was turned off not only during the period of sun rays in the windows, but also for the same time afterwards (due to heat gains from heated surfaces of walls and furniture) [15]. At the same time, it is important that the temperature of the internal air of heated buildings, i.e. indicator integrating the effect of solar radiation, infiltration of outside air and internal heat generation on the thermal regime of the building, was the signal to use the façade control.

Attempts to control the facade-divided heating systems without taking into account the internal air temperature are ineffective. By limiting control of the heat supply based on changes in the outside air temperature (even with the use of solar sensors), the thermal conditions of the building can be significantly disrupted. First, it is difficult to consider how the solar radiation on the sensor effects on the change in the heat transfer of the heating system. Second, it is problematic to determine to what decrease in the air temperature of the room will bring the wind increase towards the facade illuminated by the sun.

It should be noted that the implementation of facade control only according with the internal temperature is also undesirable, since this can lead to heat overrun. For example, when the facade system shuts off with the appearance of the sun due to the increase in the internal temperature, but the temperature remains high, residents can open the windows. After sunset, the air temperature will decrease, and heating will resume, but with increased air exchange due to open windows. Thus, the maintenance of the set heat carrier schedule in a facade multi-loop system with correction by the internal air temperature is based on the limitation of the heat supply.

In new construction, it is necessary to focus on equipping the heating devices with thermostats, since they increase comfortable conditions, allowing residents to meet their individual needs for maintaining the required air temperature. Vertical one-pipe or two-pipe heating systems with thermostats can be supplemented by façade control to increase the stability of their work, since when one of the facades is illuminated by the sun, not only 
heating devices but also the entire riser will be switched off. Control of the heat supply is performed without correction by the internal temperature. It is carried out by changing the temperature of the heating carrier supplied to the facade system, which depends on the outside temperature, measured by the sensor, which is open to light from the sun.

To account the heat consumed, a sensor is installed on each heating device with a thermostat, according to which the heat consumption measured by the house heating metering device is distributed for each apartment. It should be noted that an individual measurement of the amount of heat consumed in the presence of a thermostat on the heater should be mandatory, since it stimulates residents to save heat. Without it, residents can increase the air exchange in apartments above the required sanitary standards, which will lead to excessive heat consumption.

When using individual façade control, in contrast to central multi-loop heating, there is a risk that residents from a neighboring apartment, temporarily not living in it, in order to save, can set thermostats to maintain lowered air temperature. Calculations showed that if the apartment has a temperature of $+10^{\circ} \mathrm{C}$, then the heat losses of the rooms adjacent to it increases for $30-50 \%$ at the average winter conditions. This causes a decrease in air temperature in these rooms and an unjustified increase in heat consumption. Probably, in order to eliminate this drawback, thermostats should have a restriction on lowering the set temperature not lower than $+16^{\circ} \mathrm{C}$.

Heating systems with vertical risers are collective use systems. Opening and closing above located along the water flow thermostats affect the work of the following, especially in the vertical one-pipe heating system. Therefore, the most acceptable solution is to use apartment heating systems with double-pipe vertical sectional risers passing through the staircase, to which horizontal apartment piping are connected. These piping are usually made of reinforced plastic flexible pipes according to the radial or perimeter scheme. Heating devices are equipped with thermostats, and the apartment heat metering devices are installed to measure the heat consumed at the connection points to the risers. In municipal buildings in order to save, a common house water metering units are used, and the heat consumption in the premises is calculated according to the indications of water meters [16].

\section{Conclusions}

Implementation of multi-circuit heating systems has promising prospects. To increase their efficiency, it is necessary to modify the controls of the heat supply process, based on the timely processing the information about the monitored parameters and consideration of the mutual influence of the heating circuits.

As a result of the analysis of existing schemes and methods of heat supply, the main regularities and functional connections in the control of building heating processes were identified. It has been established that in order to minimize the energy costs for maintaining comfortable temperature conditions in buildings with changing climatic and climatic influences during the heating period, it is necessary to solve the following tasks:

- development of a mathematical model of the heat supply process when the heating system is connected to the heat network in a dependent scheme and the study of its parameters in stationary and non-stationary modes;

- creation of a model of the optimal operation mode of the heat supply system connected to the heat source in a dependent mode;

- development and study of the structure of the heat supply control system of the building at dependent connection to heat networks;

- the creation of an operation control algorithm for the multi-loop heat supply system of the building with dependent connection to heat supply networks and the development of a device for its implementation. 


\section{References}

1. A. Benuzh, S. Fedorov, E. Orenburova, MATEC Web of Conferences 251, 03052 (2018)

2. L. Mauri, A. Vallati, P. Ocłoń, Journal of Cleaner Production, Volume 214, 20 March 2019, 791-802 (2019)

3. C. Su, H. Madani, B. Palm, Energy Conversion and Management, 177, 493-510 (2018)

4. X. Li, R. Yao, W. Yu, X. Meng, B. Li, Journal of Cleaner Production, 220, 271-288 (2019)

5. S. Al Qadi, B. Sodagar, A. Elnokaly, Journal of Cleaner Production, 196, 1292-1305 (2018)

6. A. Bruce-Konuah, R. Jones, A. Fuertes, Energy and Buildings, 183, 129-138 (2019)

7. G. Gaglia, E. Dialynas, A. Argiriou, E. Kostopoulou, K. Laskos, Energy and Buildings, 183, 86-104 (2019)

8. J. Terés-Zubiaga, E. Pérez-Iribarren, I. González-Pino, J. M. Sala, Energy Conversion and Management, 171, 491-506 (2019)

9. C. Chang, N. Zhu, K. Yang, F. Yang, Energy and Buildings, 172, 104-115 (2018)

10. L. Canale, M. Dell'Isola, G. Ficco, B. Di Pietra, A. Frattolillo, Energy and Buildings, 168, 385-398 (2018)

11. M. Calero, E. Alameda-Hernandez, M. Fernández-Serrano, A. Ronda, M. Ángeles Martín-Lara, Energy and Buildings, 175, 121-130 (2018)

12. J. Terés-Zubiaga, A. Campos-Celador, I. González-Pino, G. Diarce, Energy Conversion and Management, 126, 736-747 (2016)

13. S. Rhys Jones, J. Beardmore, M. Gillott, R. Boukhanouf, G. Walker, Energy Procedia, 153, 295-302 (2018)

14. V. I. Telichenko, A. A. Benuzh, V. V. Fateeva. IOP Conf. Series: Materials Science and Engineering, 456 (2018)

15. V. I. Livchak, Journal "ABOK", 1, p. 13-14 (1999)

16. S. S. Fedorov, FORM2018 Materials Science and Engineering, 365 (2018) 